\title{
Artikel
}

\section{Giften aan afstammelingen en de legitieme: wil de ware legitimaris opstaan?}

Mr. dr. R.E. Brinkman en prof. mr. W.D. Kolkman*

\section{Inleiding}

Schenkingen, of ruimer: giften, vormen het voorportaal van het erfrecht. Door de erflater gedane giften spelen onder meer een rol bij de berekening van de legitimaire massa. Als hoofdregel geldt daarbij de vijfjaarstermijn van artikel 4:67 onder e van het Burgerlijk Wetboek (BW): voor zover de prestatie binnen vijf jaar voor erflaters overlijden is geschied, wordt de gift meegenomen in de legitiemeberekening.

Een wezenlijke uitzondering op dat lustrum staat in artikel 4:67 onder d BW: bij de berekening van de legitieme porties worden in aanmerking genomen giften, door de erflater an een afstammeling gedaan, mits deze of een afstammeling van hem legitimaris van de erflater is.

De laatste bijzin roept een onduidelijkheid in het leven. Moet de begiftigde (of zijn afstammeling) daadwerkelijk de hoedanigheid van legitimaris annemen, of volstaat het dat hij als zodanig zijn wilsrecht had kunnen uitoefenen? In het eerste geval dient zich een uitweg aan voor de begiftigde afstammeling. Indien hij weliswaar legitimaris was, maar van zijn legitimaire rechten geen gebruik maakt (door bijvoorbeeld te verwerpen zonder voorbehoud van zijn legitieme, dan wel door te berusten in een onterving), telt de door hem ontvangen gift niet mee, mits ouder dan vijf jaar.

Mr. dr. R.E. Brinkman is notaris te Hardenberg, docent aan de Rijksuniversiteit Groningen en raadsheer-plaatsvervanger bij het Gerechtshof Arnhem-Leeuwarden. Prof. mr. W.D. Kolkman is hoogleraar Algemene Rechtswetenschap en Familievermogensrecht aan de Rijksuniversiteit Groningen en adviseur bij Elan Notarissen.
In de literatuur bevinden zich enkele voorstanders van deze visie. Zie bijvoorbeeld Perrick:

'Berust een kind in zijn onterving of verwerpt het de nalatenschap zonder zich zijn legitieme voor te behouden, dan zullen de giften die langer dan vijf jaren voor het overlijden van de erflater zijn uitgevoerd niet meer voor inkorting vatbaar zijn. Op deze wijze kan een kind dat een oudere - omvangrijke gift van de erflater heeft verkregen voorkomen dat een gift op grond van art. 4:89 lid $2 \mathrm{BW}$ in verbinding met art. 4:67 BW kan worden ingekort. ${ }^{1}$

Wij kunnen ons niet vinden in deze uitleg van artikel 4:67 BW. ${ }^{2}$ In deze bijdrage bepleiten wij dat de zinsnede 'mits deze of een afstammeling van hem legitimaris van de erflater is' in artikel 4:67 onder d BW inhoudt dat giften aan een afstammeling dienen mee te tellen, zowel wanneer de afstammeling daadwerkelijk als legitimaris optreedt, als wanneer hij geen gebruik maakt van zijn legitimaire rechten. Indien iemand volgens de wet legitimaris is, vallen de hem toegekomen giften onder artikel 4:67 onder d BW. Naar onze mening behoort ook de 'oude' gift aan de verwerpende of de berustende afstammeling in de legitimaire massa te belanden en bloot te staan aan inkorting.

Voor het gemak van de lezer gaan we in het onderstaande voorbij aan de andere drie in artikel 4:67 BW genoemde uitzonderingen op de vijfjaarsperiode (dat wil

1. Asser/Perrick 4 2017/312. Zie ook Klaassen/Luijten \& Meijer II, Erfrech 2008/540 en T.J. Mellema-Kranenburg, 10 jaar nieuw erfrecht en de legitieme portie, TE 2013/6, p. 103-106.

2. Zie ook W.G. Huijgen, J.E. Kasdorp, B.E. Reinhartz \& J.W. Zwemmer, Compendium erfrecht, Deventer: Kluwer 2005, p. 65, Pitlo/Van der Burght \& Ebben, Erfrecht 2004/284 en W.D. Kolkman, Schulden der nalatenschap (diss. Groningen), Deventer: Kluwer 2006, p. 106. 
zeggen art. 4:67 onder a, b of c BW). Voor de leesbaarheid noemen we de door ons bestreden visie ook wel kortweg de concrete benadering (giften aan legitimarissen tellen op de voet van art. 4:67 onder d BW slechts mee, indien de legitimaris zich daadwerkelijk van zijn legitieme bedient). De door ons voorgestane benadering daarentegen is een abstracte (zij abstraheert van de vraag of daadwerkelijk een beroep op de legitieme is of nog kan worden gedaan).

\section{Voorbeeld}

Ter verduidelijking geven we een voorbeeld. Aart, een alleenstaande, gescheiden vader, schenkt zijn bedrijf met een waarde van $€ 390.000$ aan zijn zoon Kees. Zeven jaar na de schenking overlijdt Aart. De nalatenschap bestaat uit spaargeld ( $€ 22.000$ ). De schulden in de zin van artikel 4:7 lid 1 onder a, b, c en f BW belopen samen $€ 12.000$. Aarts enige kinderen Kees en Tina zijn ieder voor de helft erfgenaam. We veronderstellen dat er geen andere schulden tot de nalatenschap behoren dan de hiervoor genoemde en dat het saldo van de nalatenschap dus $(€ 22.000-€ 12.000=) € 10.000$ is. $^{3}$

Als Kees en Tina de nalatenschap aanvaarden en Tina een beroep op haar legitieme portie doet, zou de legitimaire massa (€ $390.000+€ 22.000-€ 12.000=$ ) $€ 400.000$ bedragen. De legitimaire aanspraak van Tina is $€ 100.000$. Haar legitimaire aanspraak wordt nog verminderd met haar helft in het saldo van de nalatenschap, ofwel met $€ 5000$. Haar legitimaire tekort bedraagt dan $€$ 95.000. Allereerst zou Tina inkorten bij Kees voor zijn aandeel in de nalatenschap van $€ 5000 .{ }^{4}$ Vervolgens vindt inkorting bij Kees als begiftigde plaats, en wel voor de resterende $€ 90.000$. $^{5}$

Indien echter de concrete opvatting wordt gevolgd, zou Kees door de nalatenschap te verwerpen kunnen ontkomen aan de inkorting door Tina. De forse gift aan Kees zou niet meetellen in het kader van de legitieme. Hetzelfde geldt ingeval Kees door Aart zou zijn onterfd en hij geen beroep op zijn legitieme doet. Dat is onzes inziens niet juist. Wij onderbouwen ons standpunt hieronder.

\section{Artikel 4:63 lid 2 BW}

Volgens artikel 4:63 lid 2 BW zijn legitimarissen de afstammelingen van de erflater die door de wet als erfgenamen tot zijn nalatenschap worden geroepen, hetzij uit eigen hoofde, hetzij bij plaatsvervulling met betrekking tot personen die op het ogenblik van het openvallen

3. In de praktijk komen geregeld ook de andere schulden van art. 4:7 lid 1 BW (die niet zijn genoemd in art. 4:65 BW) in aanmerking voor de berekening van het erfdeel van de legitimaris. Dat is van belang voor de berekening van het legitimair tekort van de legitimaris.

4. Art. $4: 87$ lid 2 BW.

5. Art. 4:89 lid $1 \mathrm{BW}$. van de nalatenschap niet meer bestaan of die onwaardig zijn. In dit eerste artikel van de afdeling getiteld 'Legitieme portie' deelt de wetgever aldus mee welke personen recht op een legitieme portie hebben. Deze identificatie vindt niet plaats door te kijken naar wat de erflater regelt, maar door te bezien wie de wet als erfgenamen tot de nalatenschap roept.

Het ligt voor de hand de omschrijving van 'legitimarissen' uit artikel 4:63 lid 2 BW ook te hanteren in de daaropvolgende artikelen. Vergelijk ook artikel 3.7 van de Aanwijzingen voor de regelgeving: hetzelfde begrip wordt niet met verschillende termen aangeduid en dezelfde term wordt niet voor verschillende begrippen gebruikt. ${ }^{6}$ Dit vormt een eerste argument voor onze abstracte zienswijze.

\section{Interne rechtsvergelijking}

Een tweede argument ontlenen wij aan het gegeven dat de concrete zienswijze in een aantal andere bepalingen van afdeling 4.4.3 BW tot onwenselijke dan wel onlogische gevolgen leidt. In lijn met de concrete visie zouden andere bepalingen die spreken van 'de legitimaris' namelijk alleen zo gelezen kunnen worden dat de in artikel 4:63 lid 2 BW bedoelde persoon al een beroep heeft (of moet hebben) gedaan op zijn legitieme portie, voordat hij als legitimaris aangeduid kan worden. Dat is in onderstaande bepalingen zodanig onwenselijk of onlogisch, dat dit naar onze mening een aanwijzing vormt dat de verwijzing naar 'de legitimaris' als een 'abstracte' in plaats van 'concrete' verwijzing moet worden beschouwd.

Artikel 4:63 lid 3 BW bepaalt dat de legitimaris die de nalatenschap verwerpt zijn recht op de legitieme portie verliest, tenzij hij bij het afleggen van de verklaring bedoeld in artikel 4:191 BW tevens verklaart dat hij zijn legitieme portie wenst te ontvangen. Hoe zou iemand die nog moet verklaren zijn legitieme portie te wensen (en daardoor legitimaris wordt), al legitimaris kunnen zijn?7 Legt hij de contantenverklaring niet af, dan verkrijgt hij geen legitieme portie. In de concrete visie zou je deze persoon dan ook geen legitimaris mogen noemen, omdat dat veronderstelt dat hij wel een beroep heeft gedaan op zijn legitieme portie. Bedoelt de wetgever niet in abstracto dat als een in artikel 4:63 lid $2 \mathrm{BW}$ bedoelde persoon verwerpt en zijn legitieme wil behouden, hij een contantenverklaring moet afleggen? In de abstracte visie zien we hier geen tegenstrijdigheid. Een soortgelijke redenering doet bij de volgende bepalingen ook steeds dienst.

6. Toegegeven, de wetgever slaagt hier in de legitiemeregeling niet altijd in. Zie bijvoorbeeld ten aanzien van de drie betekenissen van de term 'legitieme portie’ in Boek 4 BW P.C. van Es, WPNR 6544/2003.

7. Gelet op het feit dat het inroepen van de legitieme portie als een wilsrecht wordt beschouwd, is - als de legitieme portie nog niet is ingeroepen - de term 'verliezen' hier enigszins misplaatst, omdat dan niet reeds een verkregen recht verloren gaat. Juister is dat hij in het gegeven geval 'geen aanspraak meer kan maken op' zijn legitieme portie. 
Artikel 4:85 lid 1 BW bepaalt dat de mogelijkheid om aanspraak te maken op de legitieme portie vervalt, indien de legitimaris niet binnen een hem door een belanghebbende gestelde redelijke termijn, en uiterlijk vijf jaar na het overlijden van de erflater, heeft verklaard dat hij zijn legitieme portie wenst te ontvangen. Hoe kan iemand die nog (binnen de gestelde termijn) aanspraak moet maken op zijn legitieme portie en daardoor dus (pas) legitimaris zou worden, al legitimaris zijn? Bedoelt de wetgever niet in abstracto dat als een in artikel 4:63 lid $2 \mathrm{BW}$ bedoelde persoon niet binnen de genoemde termijn 'in actie komt', zijn aanspraak op de legitieme portie vervalt?

Artikel 4:87 lid 3 BW bepaalt dat het gedeelte van de nalatenschap dat aan een legitimaris toekomt en zijn legitieme portie niet te boven gaat, in afwijking van de leden 1 en 2 pas als laatste kan worden ingekort. De inkorting van dat gedeelte geschiedt alsdan, met vermindering van de vordering waarvoor wordt ingekort, zodanig dat beide legitimarissen eenzelfde evenredig deel van hun legitieme porties verkrijgen. Kan dit artikel alleen spelen als de legitimaris een beroep op zijn legitieme heeft gedaan? Staat er niet gewoon dat als een erfgenaam of legataris (of lastbevoordeelde die met geld is bedeeld) in abstracto als persoon is aangewezen als bedoeld in artikel 4:63 lid $2 \mathrm{BW}$, zijn verkrijging niet verder kan worden ingekort dan tot een bepaalde grens?

Artikel 4:92 lid 1 en 2 BW bepalen dat na het overlijden van de legitimaris zijn bevoegdheden toekomen aan hen die tot zijn nalatenschap gerechtigd zijn en dat in het geval van faillissement van de legitimaris of het ten aanzien van hem van toepassing verklaren van de schuldsaneringsregeling natuurlijke personen zijn bevoegdheden kunnen worden uitgeoefend door de curator in het faillissement onderscheidenlijk de bewindvoerder in de schuldsaneringsregeling. Hoe kan iemand al legitimaris zijn zonder daarop een beroep te hebben gedaan? In het artikel staat toch dat anderen aanspraak maken op de legitieme portie van bedoelde legitimaris? Of staat er eenvoudigweg dat bij een persoon die in abstracto is aangewezen in artikel 4:63 lid $2 \mathrm{BW}$, in bijzondere gevallen anderen (namelijk diens erfgenamen, curator of bewindvoerder) aanspraak kunnen maken op de legitieme portie die tot het vermogen van de aangewezen persoon zou hebben behoord (bij de overleden persoon) of behoort (bij de failliet of saniet) als de aangewezen persoon er zelf aanspraak op zou hebben gemaakt?

Nee, wij lezen artikel 4:63 lid 2 BW in samenhang met artikel 4:67 aanhef en onder d BW anders, namelijk dat giften aan degene die in abstracto door artikel 4:63 lid 2 BW wordt aangewezen altijd meetellen, ongeacht of deze persoon erfgenaam, legataris of lastbevoordeelde is en ongeacht of deze zelf in concreto een beroep op zijn legitieme portie doet.

\section{Parlementaire geschiedenis}

In de omvangrijke parlementaire geschiedenis van het huidige Boek 4 BW komt de centrale vraag van onze bijdrage niet uitdrukkelijk ter sprake. ${ }^{8}$ Desalniettemin zijn wetssystematische argumenten voor onze visie aan de totstandkomingsgeschiedenis te ontlenen.

In de memorie van toelichting bij artikel 4:67 BW valt te lezen dat onderdeel $\mathrm{d}$ is geformuleerd op een wijze die aansluit bij artikel 4:70 lid 2 BW. ${ }^{9}$ Laatstgenoemd artikel heeft betrekking op de toerekening van giften: de waarde van door de legitimaris ontvangen giften komt in mindering op zijn legitieme. Het tweede lid bepaalt dat voor de toepassing van artikel 4:70 lid $1 \mathrm{BW}$ giften aan een afstammeling die legitimaris zou zijn geweest indien hij de erflater had overleefd of niet onwaardig was geweest, aangemerkt worden als giften aan de van hem afstammende legitimarissen, naar evenredigheid van hun legitieme portie. Daarbij merkt de memorie van toelichting op dat - a contrario - als de begiftigde bijvoorbeeld is vooroverleden zonder achterlating van afstammelingen, artikel 4:67 onder d BW niet geldt als de prestatie langer dan vijf jaar voor het overlijden van de erflater is geschied..$^{10}$ Oftewel: de hoofdregel geldt dan weer. In dat geval werkt de toerekening dus niet door naar de personen die én erfgenaam van de begiftigde én legitimaris van de erflater zijn.

Het idee achter artikel 4:70 lid 2 BW is dat als kind A tegelijk met of vóór de erflater overlijdt of onwaardig is, terwijl hij wel afstammelingen achterlaat die legitimaris zijn, de giften aan A toegerekend worden aan die legitimarissen. In onze optiek geschiedt de toerekening ook dan, onafhankelijk van de vraag of de afstammelingen aanspraak op hun legitieme portie maken, naar evenredigheid van hetgeen ieder van hen had kunnen krijgen als legitimaris.

Stel bijvoorbeeld dat A (zoon van erflater E) twee kinderen (K1 en K2) heeft. Slechts K1 is erfgenaam van E. $\mathrm{K} 2$ is onterfd en maakt geen aanspraak op zijn legitieme portie in de nalatenschap van E. De gift aan A wordt dan voor de helft aan K1 toegerekend.

Zou A geen kinderen hebben, dan kan uiteraard geen toerekening plaatshebben bij diens afstammelingen. Stel dat erflater E naast zoon A ook zonen B en C achterlaat. Als A als begiftigde de erflater niet overleeft, terwijl alleen broer B erfgenaam van A is, wordt de gift, voor zover de prestatie langer dan vijf jaar voor het overlijden van de erflater is geschied, niet toegerekend aan B.

Het gaat er in artikel 4:70 BW dus om dat ofwel de begiftigde zelf een persoon is die is aangewezen in artikel 4:63

8. Zie Parl. Gesch. Vaststellingswet Boek 4 BW, p. 407-421 en Parl. Gesch. Invoeringswet Boek 4 BW, p. 1862-1867.

9. Zie MvT, Parl. Gesch. Invoeringswet Boek 4 BW, p. 1865. In de hoofdtekst gebruiken we de huidige artikelnummering. In de ontwerpfase heette art. 4:67 BW nog art. 4.3.3.5.

10. Het andere voorbeeld dat hier kan worden gegeven, is dat de begiftigde onwaardig is en zonder afstammelingen overlijdt. 
lid $2 \mathrm{BW}$, ofwel de afstammeling van de begiftigde een persoon is die is aangewezen in artikel 4:63 lid $2 \mathrm{BW} .{ }^{11}$ Irrelevant is of de desbetreffende persoon ook daadwerkelijk anspraak maakt op zijn legitieme portie. Op gelijke voet gaat het er in artikel 4:67 onder d BW om dat ofwel de begiftigde zelf een persoon is die is aangewezen in artikel 4:63 lid $2 \mathrm{BW}$, ofwel de afstammeling van de begiftigde een persoon is die aldaar is angewezen.

Met andere woorden, als de begiftigde zelf valt onder de omschrijving van artikel 4:63 lid $2 \mathrm{BW}$, wordt de gift ook buiten de vijfjaarstermijn toegerekend. Dat geldt zowel bij onwaardigheid alsook bij verwerping, onterving of vervallenverklaring van diens erfrecht. ${ }^{12}$ Ingeval de begiftigde geen afstammelingen heeft, ontbeert artikel 4:70 lid 2 BW werking. Zo ook geldt dat als de begiftigde de erflater niet overleeft of de begiftigde onwaardig is én (in beide situaties) de begiftigde geen afstammelingen nalaat, artikel 4:67 onder d BW niet van toepassing is op de gift aan de begiftigde. In die situaties is enkel voor de hoofdregel van artikel 4:67 onder e BW een rol weggelegd: is de begiftigde onwaardig of vooroverleden, maar is de prestatie binnen vijf jaar voor het overlijden van erflater geschied, dan kunnen de legitimarissen alsnog terecht bij de begiftigde (bij onwaardigheid) of diens erfgenamen (bij vooroverlijden).

\section{Overige argumenten}

We geven ook nog een analogisch argument. De legitieme portie van een legitimaris wordt niet groter doordat een erfgenaam de nalatenschap verwerpt of is onterfd. Dat komt doordat de wet 'in abstracto' bepaalt hoe groot de legitieme portie is (zie art. 4:64 BW). ${ }^{13}$ Zo ook bepaalt de wet 'in abstracto' welke personen legitimaris zijn. Dit is in lijn met het erfrechtelijke uitgangspunt dat de legitieme portie een dwingende aanspraak behelst, waarvan de omvang niet (althans nauwelijks) door het handelen van de erflater, erfgenamen en derden kan worden beïnvloed.

Tot slot nog eenmaal terug naar het voorbeeld. Het ene kind, Kees, ontving een forse gift. In de door ons bestreden visie zou hij door een verwerping ontkomen aan een inkortingsactie door zijn zus. Het enkele feit dat de gift ouder is dan vijf jaar roept een anzienlijke ongelijkheid in het leven tussen afstammelingen van de erflater. Wij vinden dat moeilijk te rijmen met een van de grondgedachten achter de legitieme portie, te weten het nastre-

11. In het hierboven genoemde voorbeeld zijn dat $A$ en diens eventuele afstammelingen, maar niet B (en C). Dat broer B in dat voorbeeld zelf ook legitimaris is, betekent niet dat de gift aan broer A (die mogelijk nog deel uitmaakt van de nalatenschap van broer $A$ die op broer $B$ is overgegaan) aan de legitieme van broer B toegerekend wordt.

12. Bij verwerping, onterving en vervallenverklaring van het erfrecht kan art. 4:70 lid 2 BW niet spelen, enkel eventueel art. 4:70 lid 1 BW. Wellicht is hierdoor de verwarring ontstaan ten aanzien van art. 4:67 aanhef en onder d BW.

13. Zie ook Huijgen e.a., Compendium erfrecht, p. 65: de door ons voorgestane visie doet meer recht aan de keuzes gemaakt in art. 4:64 BW. ven van een bepaalde mate van gelijkheid tussen afstammelingen van de erflater. ${ }^{14}$

\section{Recente jurisprudentie}

$\mathrm{Na}$ het schrijven van de eerste versie van onze bijdrage wees het Gerechtshof Arnhem-Leeuwarden een arrest onder meer over artikel 4:67 BW, dat wij graag (in de 'drukproeffase') nog meenemen. ${ }^{15}$ Het ging daarbij om een erflaatster die twee dochters achterliet. De ene had zij tot enig erfgename benoemd. Ook ontving deze dochter diverse schenkingen van erflaatster, langer dan vijf jaar voor het overlijden van laatstgenoemde. De erfgename-begiftigde maakt geen gebruik van haar legitimaire aanspraken. Tellen de 'oude' giften die erflaatster aan deze erfgename deed mee bij de legitieme portie van de onterfde dochter? Het hof overweegt in heldere bewoordingen:

'Evenals de rechtbank is het hof van oordeel dat voor het zijn van "legitimaris" in de zin van artikel 4:67 lid d BW niet relevant is of een beroep op de legitieme portie is gedaan of niet. Het woord "legitimaris" in artikel 4:67 lid d duidt de persoon aan die aanspraak kan maken op een legitieme portie, niet slechts de persoon die dat ook daadwerkelijk heeft gedaan. Steun voor deze uitleg biedt de omschrijving die (...) artikel 4:63 lid $2 \mathrm{BW}$ geeft van legitimarissen, te weten afstammelingen van de erflater die door de wet als erfgenamen tot zijn nalatenschap worden geroepen. In deze omschrijving is niet tevens opgenomen dat deze afstammeling ook daadwerkelijk een beroep moet hebben gedaan op zijn legitieme portie om legitimaris te zijn. Ook lid 3 van artikel 4:63 BW onderstreept deze uitleg. (...) Ook in die bepaling is met legitimaris aangeduid degene die een beroep kan doen op de legitieme portie, niet degene die dat al heeft gedaan. De beperkte uitleg die appellante [de enig erfgename; RB \& WK] geeft an het woord "legitimaris" in deze bepaling zou ertoe kunnen leiden dat de giften die moeder aan haar zuster heeft gedaan wel alle meetellen bij de berekening van de legitieme portie, maar van de giften aan appellante zelf alleen de giften die binnen vijf jaar voor het overlijden van hun moeder zijn uitgevoerd (voor zover ze niet vallen onder artikel 4:67 lid a-c BW), en dat alleen omdat appellante geen aanspraak heeft gemaakt op haar legitieme portie. Zij hoefde zich daarop ook niet te beroepen, omdat zij tot enig erfgename is benoemd en niet is gebleken dat haar legitieme portie is geschonden. De beperkte uitleg van appellante zou ook leiden tot een ongelijke behandeling van appellante en geintimeerde, terwijl de wet nu juist aan beiden een gelijke mogelijkheid biedt om in weerwil van giften en uiterste wilsbeschikkingen van hun moeder aanspraak te

14. Zie daarover bijvoorbeeld A. Pitlo, De legitieme portie (preadvies voor de Broederschap der Candidaat-Notarissen), 1954.

15. Hof Arnhem-Leeuwarden 6 februari 2018, ECLI:NL:GHARL:2018:1168. 
maken op een gedeelte van de waarde van haar vermogen. Het ligt niet in de rede dat de wetgever een dergelijke ongelijke behandeling mogelijk heeft willen maken. Dat betekent dat alle giften aan een afstammeling (mits deze of een afstammeling van hem legitimaris is) gedaan, ook indien deze langer dan vijf jaar voor het overlijden van de erflater zijn gedaan, op grond van artikel 4:67 aanhef en sub d BW bij de berekening van de legitieme portie in anmerking genomen dienen te worden, ongeacht of deze afstammeling daadwerkelijk een beroep op de legitieme portie heeft gedaan.'

Gelet op wat wij schreven in de paragrafen 1 tot en met 6 zal het niet verbazen dat wij van harte instemmen met het arrest van het hof.

\section{Conclusie}

In onze optiek heeft artikel 4:67 aanhef en onder d BW niet alleen het oog op giften aan degene die als zodanig als legitimaris optreedt, maar ook op giften aan degene die door artikel 4:63 lid $2 \mathrm{BW}$ in abstracto als 'legitimaris' wordt aangewezen, ongeacht hoe deze persoon in de nalatenschap optreedt. 'Legitimaris' in artikel 4:67 onder d BW is de afstammeling van de erflater die door de wet tot zijn nalatenschap wordt geroepen. Deze bepaling loopt in de pas met artikel 4:63 lid $2 \mathrm{BW}$. 